\title{
LAS LEYES DE VIOLENCIA DE GÉNERO EN MÉXICO: MEDIDAS DE PREVENCIÓN Y SENSIBILIZACIÓN
}

\author{
Marcela LAGARDE Y DE LOS RÍOS \\ CATEDRÁTICA DE ANTROPOLOGÍA \\ UniVERSIDAd NACIONAL AUTÓNOMA DE MÉXICO
}

El martes i6 de octubre de 20I2, Marcela Lagarde y de los Ríos ofreció una conferencia en la Universidad de La Rioja. El presente documento recoge la transcripción de la misma.

Esta actividad, enmarcada dentro del «Seminario Permanente del Departamento de Derecho», fue organizada por el grupo de investigación Igualdad y Género y el Proyecto: «La incidencia de la violencia en la eficacia de los derechos» (DER2OIO-20826-Co2-02) de la Universidad de La Rioja (UR).

La conferencia tuvo lugar entre las i9 y 2i horas en el Aula Magna del Edificio Quintiliano de la UR ya que, aunque en un principio estaba prevista su realización en la sala de grados de este mismo edificio, el interés que suscitó la conferenciante obligó a quienes organizaban la actividad a buscar un espacio con mayor aforo.

El público asistente superó las doscientas personas y fue de gran diversidad en cuanto a edad, formación e intereses, pues allí se reunieron el alumnado de distintos cursos del Grado de Derecho, de los primeros cursos del Grado de Maestro en Educación Primaria y en Educación Infantil y del Grado de Trabajo Social, profesorado de estos grados, antiguos estudiantes de la UR, riojanos y riojanas pertenecientes a diversos colectivos sociales, miembros de ONGD y profesionales de diversos ámbitos e instituciones interesados por el tema de la igualdad, la violencia y el género, etcétera.

Ante este auditorio tan plural, Marcela Lagarde presentó el tema objeto de su plática de forma que atendiera a la diversidad de asistentes, haciendo una presentación general y evitando profundizar en exceso, dada la infinidad de intereses y la variedad de niveles educativos de los participantes.

El texto que se presenta a continuación es un reflejo fiel de lo que esa tarde se dijo y presenta por ello las características propias de un testimonio oral que ha sido transcrito a formato escrito. Para quienes deseen profundizar en el tema objeto de esta conferencia, les

\footnotetext{
${ }^{\text {I }}$ Presentaron la conferencia la profesora $\mathrm{M}^{\mathrm{a}}$. J. Clavo y el profesor Raúl Susín, en representación, respectivamente, del Grupo de Investigación Igualdad y Género y del Departamento de Derecho de la Universidad de La Rioja.
} 
remitimos al artículo de esta misma autora: «El derecho humano de las mujeres a una vida libre de violencia de género» [http://freedownloadb.com/pdf/el-derecho-humano-de-lasmujeres-a-una-vida-libre-de-violencia-32257594.html], o a alguna de sus numerosas publicaciones, entre las que destacamos:

- Los cautiverios de las mujeres: madres, esposas, monjas, putas, presas y locas (tesis doctoral).

- Género y feminismo.

- Desarrollo Humano y democracia.

- Claves feministas para el poderío y la autonomía de las mujeres.

- Claves feministas para la autoestima de las mujeres.

Marcela Lagarde y de los Ríos, mexicana, es catedrática de antropología en la Universidad Nacional Autónoma de México y una de las representantes más destacadas del feminismo latinoamericano actual. Es profesora de los Posgrados de Antropología y de Sociología de la Universidad Nacional Autónoma de México y asesora del Programa de Género del Centro de Investigaciones Interdisciplinarias en Ciencias y Humanidades de la Universidad Nacional Autónoma de México. Su sólida trayectoria académica e investigadora incluye la publicación de más de cien artículos y es también autora de varios libros. En 2003 se presentó a las elecciones mexicanas como candidata independiente en las listas del Partido de la Revolución Democrática (PRD) y ocupó el cargo de diputada en el Congreso Federal de México entre 2003 y 2006. Durante esa legislatura destacó su trabajo a favor de los derechos de las mujeres.

Ha acuñado el término «feminicidio» para describir la situación de violencia extrema que afecta a las mujeres en México. Durante su etapa como diputada del Congreso mexicano impulsó la creación de una Comisión Especial de Feminicidio para investigar los asesinatos de mujeres en la localidad mexicana de Ciudad Juárez. En ese periodo dirigió una «Investigación Diagnóstica sobre Violencia Feminicida en la República Mexicana», mediante la que se descubrió que el feminicidio no es exclusivo de Ciudad Juárez sino que también acontece en otras zonas del país. Promovió la tipificación del delito de feminicidio en el Código Penal Federal y de la Ley General de Acceso de las Mujeres a una Vida Libre de Violencia, ley vigente en México desde el 2 de febrero del 2007.

\section{Marcela Lagarde}

¿Cómo están? ¿Qué quieren que les cuente? A mí me gusta mucho contar y sobre todo si hay interés de ustedes por el tema.

Yo podría hacer una conferencia muy técnica sobre la ley, pero me parece que en una universidad y ante un auditorio de estudiantes y maestras y maestros que se están formando e investigando en muy diversos temas es importante que sepan sobre estos temas; y lo digo por cómo me preguntan los periodistas, como si estos problemas sólo los hubiera en México y la verdad es que aunque varían mucho en el mundo, no sólo los hay en México.

Es importante que sepan, como dijo el colega que estaba aquí (en referencia al prof. Susín), que efectivamente las leyes no nos hacen buenas personas pero las leyes a veces son indispensables para convivir. Y en una gran cantidad de países del mundo contemporáneo ha habido un cambio jurídico importante que ha consistido en detectar la necesidad de leyes para enfrentar la violencia contra las mujeres. Y esto es una marca de los 
tiempos. En los últimos treinta años se ha legislado en gran parte del mundo occidental para disminuir, como se dijo aquí, la violencia contra las mujeres, pero también, en otras ocasiones, para ubicar esa violencia cuando no ha sido reconocida como tal, como parte de lo que han llamado en muchos países violencia intrafamiliar.

En el caso de México y América Latina, por una enorme influencia del Vaticano, hace unos veinte años, cuando los movimientos feministas propusimos en varios países una estructura legal, una estructura jurídica para enfrentar la violencia, la respuesta fue que, no sólo no había violencia contra las mujeres, sino que en el ámbito familiar las mujeres también somos violentas. Violentamos a las criaturas, al educarlas, violentamos a las personas mayores o podemos violentar a personas enfermas que dependen de nuestra atención y nuestros cuidados por la forma en que está organizada la vida social, familiar, cotidiana y privada.

Con ese argumento yo digo que tuvimos una derrota muy fuerte cuando se legisló para afrontar la violencia familiar y ahí se subsumió la violencia contra las mujeres y las niñas. En primer lugar, porque no sólo vivimos violencia las mujeres en el ámbito familiar, también vivimos violencia en espacios públicos. Entonces en esa legislación se dejó fuera toda esa otra violencia que ocurre en el espacio público. Pero también había otro argumento muy importante y creí escuchar algo en lo que tú dijiste, que era el tema de por qué hacer leyes específicas para la violencia contra las mujeres. Eso rompía con la igualdad ante la ley.

Con ese argumento y otros muchos, y por una intensa campaña del Vaticano y de partidos conservadores, cuando esta propuesta legislativa llegó a los Congresos de Brasil, de México, de Costa Rica, de Argentina, de Ecuador, de Colombia y de otros países, diputadas y diputados rechazaron la propuesta de legislar para afrontar la violencia contra las mujeres.

Se aprobaron leyes que se llaman de violencia familiar o intrafamiliar, según el lugar, y ahí quedó incorporada la violencia que vivimos las mujeres. Bueno, el hecho es que se crearon instituciones para tramitar las denuncias, se crearon agencias, ministerios públicos y espacios de protección y atención a las víctimas de esta violencia. La atención psicológica y la atención legal fueron como las dos, digamos, líneas de trabajo para atender a mujeres, hombres, niñas, niños, mayores, menores víctimas de violencia intrafamiliar.

\section{¿Hasta ahí me siguen? Bueno.}

Resulta que en estos veinte años pasaron muchas cosas. En México, que he seguido el caso, más del $95 \%$ de las denuncias de violencia intrafamiliar fueron hechas por mujeres, viejas y jóvenes, por mujeres adultas que denunciaron violencias a las que estaban sometidas niñas y adolescentes. También los niños, cuando forman parte del ámbito femenino, han sido víctimas de violencia. El tema no lo hago largo pero decir que también se optó por tipificar delitos. Se tipificó, aunque ya estaba en algunos códigos en América Latina, la violencia sexual. Se definió qué era violencia sexual, se legisló de nuevo en torno a la violación, aunque ya estaba legislada en códigos anteriores, y también se definió qué es la violación.

Con los años y muchos esfuerzos fuimos logrando que se legislara el acoso sexual y también el hostigamiento sexual. Y hasta ahí llegamos, no dio para mucho más pero sí para que en universidades se crearan, se introdujeran en los estudios de Derecho, en los estudios de Psicología, materias ligadas a la legislación de violencia intrafamiliar, sexual, etcétera. Y se fueron formando especialistas, sobre todo en la atención a las víctimas de violencia, tanto en el campo de la Psicología, como en el campo del Derecho, e incluso se crearon masters especializados en esta legislación y en sus consecuencias institucionales y de políticas públicas, o bien de atención privada por profesionales privados en los mismos campos que dije. 
No les voy a contar toda la historia de mi país, pero para entender qué nos pasa habría que saber su historia. Decirles que en México la violencia está incluida en la mayor parte de las ideologías; o sea, en México hemos sido educadas y educados, mujeres y hombres, en ideologías violentas. El nacionalismo revolucionario tiene una columna vertebral violenta. Yo fui educada en que las revoluciones armadas eran lo mejor que nos podía pasar. Por ejemplo, mi país estaba surcado por calles que se llaman Insurgentes, Reforma, Revolución, etc. Las calles principales de los pueblos llevan los nombres de los héroes que nos dieron patria. Lo digo porque eso es parte de mi cultura, de mi historia. Recorro mi ciudad y desde el punto de vista de la perspectiva de género y urbanismo puedo detectar que la mayor parte de las esculturas que todavía se ven en mi país son esculturas de hombres armados a caballo y los que están desarmados van a pie.

En fin, el tema es complejo, no sólo está el machismo con una exaltación enorme a los hombres violentos, una exaltación a la virilidad violenta que todas y todos conocen. No les voy a contar del mariachi mexicano, ni les diré tampoco que el himno nacional mexicano empieza diciendo «mexicanos, al grito de guerra, el acero aprestad y el bridón, y retiemble en sus centros la tierra, al sonoro rugir del cañón». Y eso lo cantan niñas y niños todavía. Con referencia a los mariachis, «Y sigo siendo el rey», que podemos cantar destempladamente mujeres y hombres, es considerado popularmente como el segundo himno nacional.

Con relación a ello voy a referirles una anécdota. Una vez fui a Baeza, a la Escuela de Formación Feminista de Andalucía que tiene allí el Instituto Andaluz de las Mujeres, que es un lujo la escuela. Había un grupo, creo que de Córdoba. Pasamos todo el día en seminarios, exposiciones y performances, y por la noche cuando me subí a dormir yo oía un canto, pero como padezco de sordera no entendía en eso nada conocido. Me asomé así a la puerta a oír qué entonaban las mujeres cordobesas, y estaban cantando «Y sigo siendo el rey», a las tres de la mañana, para agradar a su profesora mexicana que vino del otro lado del Atlántico. Al otro día, en la sesión, mencioné el tema para explicar cómo el machismo no muy silenciosamente, estridentemente, se transmite a través de la música, del folclore y de todo eso que aparentemente no daña a nadie, pero daña a muchísima gente. Nos fuimos a dormir de nuevo, y como a las dos de la mañana oigo algo conocido, pero era otra canción. Fui a verlas y lo que cantaban era «Y sigo siendo la reina». Y entonces ya creían que era maravilloso porque ya no era el rey, ya era la reina. Y la verdad, tuvimos que analizar que las feministas, los hombres feministas y la mujeres feministas, no nos proponemos un mundo al revés, de dominación de las mujeres, como ellas lo cantaban.

El tema del machismo, el patriarcado, la misoginia, es complejo. Está efectivamente en la cultura, se transmite en las canciones, en los chistes, en el lenguaje. El lenguaje es profundamente sexista, es enormemente machista, androcéntrico. En muchos lugares se habla en masculino como nunca antes del siglo XX se habló en México. Antes del siglo XX se hablaba con géneros, pero en el siglo XX se masculinizó enormemente el mexicano, el castellano de allá, que además de ser enormemente masculino, es muy hostil. Hay un lenguaje muy hostil, muy misógino contra las mujeres. Y también debo decir que el trato es discriminatorio, que hay una gran desigualdad con respecto a las mujeres. Si una llega a México con ojos de mirar, como si llegara a cualquier otro país del mundo con guerras de género, vería qué misógina y machista es la cultura.

Pero no sólo es la cultura, y a eso me quería referir para entroncar con la ley. Es la sociedad y sus profundas estructuras las que soportan esta cultura tan patriarcal. No es sólo la cultura, no son sólo las formas, no es sólo el lenguaje, no son sólo valores en el aire, desigualdad ideológicamente construida, no. Hay una estructura social de gran desigualdad entre mujeres y hombres y, efectivamente, ha habido cambios importantísimos desde el XIX hasta el XX, todo el siglo XX en México y en América Latina en general, de tal manera que hemos reformado el patriarcado, no sólo los movimientos feministas, también los liberales, los socialistas, los anarquistas. Los diversos revolucionarios que ha habido en México han 
ido construyendo cambios importantes en la relación entre mujeres y hombres, cambios sociales, profundos cambios familiares, cambios comunitarios. Y tampoco tardaré mucho en decir que México pasó de ser un país agrario, después de la revolución de I9ıo, a ser un país urbano e industrializado, pero tiene resabios de una gran cultura anclada en el pasado, en el mundo de los charros, de los caballos, aunque es cierto que ese mundo ha ido desapareciendo poco a poco.

El país es un país mayoritariamente urbano, pero también hay un mundo rural y un mundo indígena y, junto a ello, un enorme racismo. Hay exclusión de las personas por su origen étnico, por su fenotipo, exclusión racial y étnica. Esos hombres y mujeres están en desigualdad con el resto de las personas. Todos somos mexicanos y mexicanas, pero efectivamente las clases sociales, las etnias y las razas están estructuradas de manera supremacista, y eso se advierte en la sociedad casi a primera vista.

He señalado todo esto para que comprendamos las múltiples estratificaciones sociales, las múltiples ideologías que alientan las discriminaciones y también los cambios que ha habido. Las mujeres en México tenemos derecho a la educación y por fin hay educación universal primaria. Ya por ley está la secundaria y ahora acabamos de aprobar la preuniversitaria como educación obligatoria. La educación universitaria se reduce mucho más. Quienes terminábamos carreras universitarias éramos poquitas, aunque cada vez somos más mujeres, en todas las disciplinas: Humanidades, Ciencias de la vida, Filosofía, Ciencias sociales, Políticas o de la Comunicación. Cada vez hay más graduadas universitarias, lo que no es óbice para que en esas facultades y en esas escuelas quienes ocupan los puestos directivos sean hombres, que a su vez se resisten enormemente a los estudios de género, pues muchísimas veces quienes están en situación o en posición académica de poder no se acercan mucho a la innovación tan importante que ha significado la perspectiva de género en la formación universitaria, en la sociedad y en las leyes.

La ley que yo les voy a presentar ahora, que es la que hicimos entre 2003 y 2006 , se aprobó veinte años después de la Ley de Violencia Intrafamiliar, y es también posterior a la admisión de feminicidio. Hay un antes y un después del feminicidio en México, tanto en conciencia de género como en movimientos exigiendo justicia frente a la impunidad y todo lo que ha seguido a los crímenes de mujeres y niñas en Ciudad Juárez, específicamente. Esta ley surge después de que en Ciudad Juárez se detecte, por parte de grupos y organizaciones de mujeres, sobre todo feministas, que aparecen crímenes a diario en la prensa contra mujeres y niñas, pero que son tratados de manera amarilla. Aquí ¿dicen amarilla o roja? Bueno, pues en la nota roja de manera amarillista, la prensa describe generalmente de forma despiadada y cruel lo que se encuentra en los cuerpos de mujeres que han sido violentadas hasta la muerte, y así se inicia un movimiento social fruto del cual se van aprobando leyes. Son leyes motivadas por un reclamo social, civil. Las leyes no salen porque sí, no emergen por generación espontánea. En Ciudad Juárez y en el país entero, los movimientos feministas fuimos reclamando justicia y fuimos reclamando fin a la impunidad, porque en esa época, estoy hablando de I994, empezamos a detectar que esos horribles crímenes contra mujeres y niñas quedaban en la impunidad, es decir, no había acceso a la justicia por parte de los familiares de las víctimas.

Pasó el tiempo y no hubo justicia en el Estado de Chihuahua, que es donde queda Ciudad Juárez, y tampoco hubo justicia apelando al Gobierno Federal y a otros niveles, hasta que la gente empezó a salir de México y recorrió diferentes países, España entre ellos, denunciando todo eso. Yo he encontrado grupos solidarios con las víctimas de violencia en Ciudad Juárez en diversos ayuntamientos, ciudades, asociaciones de mujeres y redes feministas españolas. En esta situación me convencí de que era importante y necesario ir al Parlamento para poder enfrentar ese problema desde dentro. Y llegué a la Cámara de Diputados como una diputada federal más, pero rápidamente tuve gran apoyo de mi grupo parlamentario ante ese problema. Y entonces promoví, como antropóloga, un estudio diagnóstico que para mí es, tal vez, el trabajo más fuerte que he hecho en mi vida de 
investigadora, porque es la mera investigación que se ha desarrollado en México sobre la violencia feminicida, sobre todos los tipos y modalidades de violencia y, en particular, aquella que conduce a la muerte violenta de mujeres.

Hicimos la investigación diagnóstica con muchísimas resistencia y dificultades, haciendo política parlamentaria fuera del Congreso. Fuimos a recorrer el país, a hablar con los gobernadores, los procuradores, a exigir cifras, datos, hasta que se cansaron y tuvieron que empezar a contestarnos. Sistematizamos todo el material y los datos obtenidos rápidamente, en cuatro meses, y pudimos elaborar el proyecto que llegaría a ser ley, ley que está amparada, avalada, fundamentada en esa investigación. En México, como Estado federal, hay leyes federales. Sin embargo, y considerando que el movimiento feminista no tenía la fuerza suficiente para impulsar una ley federal, dado el alto porcentaje de votos requeridos para su aprobación (tres cuartas partes del Congreso y en las tres cuartas partes de las entidades federativas), se optó por una ley general, una ley marco de obligado cumplimiento en todo el país y que puede asignar responsabilidades al Estado. La Ley General de Acceso a una Vida Libre de Violencia obliga al Estado a intervenir de forma directa para evitar cualquier tipo de agresión contra mujeres y niñas. Me gusta mucho el nombre de esta ley porque es de acceso $a$.

Quiero citar a dos personas. Una es Martha Nussbaum, connotada filósofa e investigadora que ha trabajado mucho el tema del desarrollo de capacidades sociales y del desarrollo mismo. Le van a dar el premio Príncipe de Asturias, por eso le dedicó «Babelia» un reportaje buenísimo en el ejemplar de anteayer que recoge toda su obra filosófica, y que les recomiendo. Pero no me voy a centrar en Martha, les voy a hablar de su colega que se llama Amartya Sen y que es economista, el único economista que ha merecido el Premio Nobel sin ser neoliberal y que es el gran teórico del desarrollo humano sostenible. Ellos crearon el concepto de acceso, y lo crearon para hacer notar que teníamos que encontrar no sólo los grandes rubros de solución a los problemas sociales, económicos, políticos, etcétera, sino que teníamos que mostrar las rutas, los caminos; a eso le llamaron «el acceso». Este acceso es importante porque, en general, el sujeto del mismo es la mujer.

Me encantó tu introducción (se dirige a la profesora Clavo) aclarando que no somos la mujer, sino que somos las mujeres, y decimos las mujeres, en plural, porque somos millones de mujeres, y además por la diversidad de formas de ser mujer que tenemos las mujeres en el mundo. Y esto lo digo porque en los últimos treinta años ha habido una modificación del lenguaje, no sólo hablamos en femenino y masculino cada vez más, sino que además en lenguaje que reconoce la diversidad, y eso es muy importante. Somos las mujeres las que podremos tener ese acceso a una vida libre de violencia. Esa vida libre de violencia, simplemente decirlo es maravilloso. Es el primer derecho que reconoció el tribunal que se constituyó a instancias de la Cumbre de Viena de I993.

¿Ya sabían de la Cumbre de Viena?

A todos nos compete, sobre todo a las mujeres y a los hombres, saber que no fue hasta 1993 cuando a instancia del Derecho Internacional, de los Derechos Humanos, se reconocieron los derechos humanos de las mujeres. Fuimos consideradas seres humanas, no seres humanos, con derechos específicos. Y el primer derecho que reconoció la Cumbre de Viena a las mujeres fue el derecho a la vida. Después se cayó en la cuenta de que no bastaba con reconocer el derecho a la vida, sino que tenía que ser derecho a la vida sin violencia y que enunciarlo como un derecho humano era un compromiso universal de los derechos humanos. Fundamentada en ello, la ley mexicana se denominó como Ley General de Acceso a una Vida Libre de Violencia.

Quiero decir que a mucha gente se le traba la lengua al decir el nombre de la ley, sobre todo cuando la dicen de memoria, porque quieren poner la palabra «contra» en algún lado, porque muchas leyes son contra la violencia y así se han aprobado en muchos 
parlamentos y congresos del mundo. Porque efectivamente hay una acción contra la violencia, pero a nosotras, como hicimos una ley más tardía, nos pareció mejor llamarle con el derecho humano que alberga esta ley. El bien jurídico que tutela esta ley es el derecho humano de las mujeres a la vida. Eso es importante, porque en la discusión de si era constitucional o no, era importante que se identificara cuál es el bien tutelado, y es este. Los principios que están a lo largo de toda la ley son varios principios fundamentales que, a veces, allá fuera, en la calle, se usan casi como adjetivos; pues quién sabe qué cosa rara es eso de la igualdad, eso de la no discriminación o, por ejemplo, este principio articulado en dos ejes que son tanto la dignidad como la integridad de las mujeres, la libertad y la seguridad.

Sabemos que todos los derechos humanos son en teoría indivisibles, esa es una de sus características, por eso son derechos humanos y no simples derechos sociales o civiles o políticos, son universales, abarcan a todas las mujeres de cualquier condición, identidad, etnicidad o edad. Todas las condiciones están incluidas por la universalidad del derecho, pero también decir que los derechos y sus principios a veces se contraponen, por ejemplo, el de la libertad y el de la seguridad.

Para muchos, más seguridad se puede conseguir con mucha vigilancia. Por ejemplo, en México, antes de esta ley, nos querían convencer de que con más policías, con más cámaras en las calles, en los edificios, en todas partes, íbamos a lograr mayor seguridad. Del mismo modo, si las mujeres salimos menos de la casa estaremos menos expuestas a la violencia privada; si no vamos por la noche de copas con nuestros cuates o cuatas también estaremos protegidas de la violencia, o sea, que la seguridad pelea con la libertad.

No puedo explicar, en el tiempo que tengo, cómo se articulan todos los principios en cada artículo de la ley, en cada capítulo, pero es importante que lo sepan ustedes, que es muy complicado poder preservar libertades y además construir seguridad; poder preservar el respeto a la dignidad de las mujeres sin entrometernos, digamos invasivamente, en su propia autodignidad y autoestima es complejo.

Esta ley armoniza varios instrumentos jurídicos. Uno, importantísimo, es la Convención para la eliminación de todas las formas de discriminación contra las mujeres. Muchas personas consideran que esta es la verdadera carta de derechos humanos de las mujeres. ¿Alguien ha leído esa convención? No se preocupen, está en las bibliotecas o está en Internet, entran ahí y ponen «CEDAW» y van a leer una de las piezas magistrales del Derecho Internacional, un instrumento vinculante, de obligado cumplimiento para todos los gobiernos que la suscriben y que son parte del pacto de la ONU. Quienes se reunieron en I98I para discutir esta Convención e hicieron la declaración, consideraron que es posible eliminar todas las formas de discriminación contra las mujeres. Piensen en el verbo eliminar, y no sólo disminuir, que es importante.

Muchos planes internacionales y nacionales sólo buscan disminuir algún problema, disminuir las consecuencias de la violencia, disminuir los robos, disminuir el hambre, como, por ejemplo, lo que se llama Objetivos del Milenio. Esos objetivos son ocho y buscan disminuir, por ejemplo, la pobreza. Ese es el primer Objetivo del Milenio para el mundo entero, para quienes están en la ONU, pero también hay un Objetivo del Milenio que busca disminuir la violencia hacia o contra la mujer. Este instrumento se plantea eliminar todas las formas de discriminación y es una apuesta importante pensar el presente con visión de futuro. Se coloca en el futuro la eliminación de todas las formas de discriminación, porque sólo en el futuro podrá lograrse. Especifica lo que podemos hacer ahora, en el presente, o a qué estamos comprometidos. Es fundamental pensar que hoy necesitamos emprender acciones para eliminar todas las formas de discriminación contra las mujeres y las niñas. 
Hace unos días se conmemoró por primera vez el Día Mundial de las Niñas para llamar la atención sobre las necesidades de las niñas en el mundo, sobre los derechos específicos de las niñas. Hace unos días a una niña pakistaní alguien le dio un plomazo en la cabeza para callarla, y esa niña está a punto de morir, y está muy dañada sólo por exigir el derecho a la educación para las niñas pakistaníes. Y justo se estaba conmemorando ese día para llamar la atención de cómo hay formas específicas de discriminación contra las niñas que debemos reconocer, visibilizar y enfrentar, y pasó esto.

El pasado día I5 fue el día, todavía se llama, de la mujer rural, o de las mujeres rurales, y ahora se le ha añadido «e indígenas», que se conmemora hace muy poquito, desde 2008, y que es para llamar la atención de las discriminaciones específicas de mujeres en el mundo rural. Y así se han ido creando días y espacios simplemente para sumar esfuerzos y sensibilizar sobre ese problema o esa problemática específica de mujeres, de niñas indígenas, o no indígenas, en el mundo rural.

Cuando decimos que la ley está armonizada quiere decir que tomamos muchos aspectos de esa declaración y que los convertimos en contenido de la ley. Para unificar nomenclatura, para homogeneizar las categorías jurídicas, quienes nos dedicamos a estudios de género, a investigación, a las leyes, quienes estamos en movimientos de mujeres, feministas, o de mujeres y hombres por los derechos humanos, hablamos de discriminación y citamos la CEDAW. Si alguien tiene que hacer un trabajo de alguna materia sobre discriminación no vaya al diccionario, vaya a la CEDAW y busque las definiciones científicas, consensuadas con una perspectiva muy democrática y progresista sobre la discriminación.

La otra fuente es la convención Interamericana, que sólo está vigente en América porque el organismo que avaló esta convención fue la OEA, la Organización de Estados Americanos. Ustedes tendrían, por ejemplo, la Unión Europea como algo que podría parecerse a nivel de Derecho Internacional. Y esta convención se hizo años después. Si se fijan en las fechas, así como en México hemos estados preocupadas y ocupados por el tema del feminicidio y las violencias, en América Latina también. Y ahí ha habido una visibilidad cada vez mayor; se sabe más, se investiga más sobre violencia contra las mujeres y las niñas. Se vio que no era suficiente con la CEDAW, sino que tenía que haber un instrumento específico para plantear una alternativa, una salida a la violencia contra, decían todavía, la mujer.

Pero fíjense qué interesante. Ésta plantea tres ejes, no sólo dos. No sólo señala prevenir. Es una ley en general para enfrentar la violencia, pero en el propio título de la convención recoge los ejes de las políticas de Estado que deben aplicarse para poder enfrentar la violencia. Uno es prevenirla, o sea, que la gente que hizo eso estaba convencida de que es posible anticiparnos y crear, con ciertas medidas, eso que se llama prevención, anticipándonos al hecho y además, jojalá!, lograr que no se produzca. Ese es el objetivo, prevenir, sancionar, porque también se reconoció que mientras no haya sanción a este delito, mientras no se considere delito, la violencia se normaliza y se considera parte de la idiosincrasia, parte de la cultura propia, parte de un etnos, parte de una identidad y la mera verdad; convertir en delito la violencia implica que haya una sanción, sanción penal y también sanción social de este delito.

Me encanta decir que esa convención ha considerado que es posible erradicar la violencia contra las mujeres. Utilizaron ese concepto, y lo explican en la exposición de motivos, para determinar que hay que ir a la raíz de qué es lo que genera la violencia contra las mujeres. Y lo que dicen en esta convención, como lo dice la ley de medidas para enfrentar la violencia de género en España, lo dice en la entrada la ley de ustedes, la violencia se genera en la desigualdad enorme entre mujeres y hombres en la sociedad. Y además se considera que la violencia es un recurso de dominación de género y con ese enfoque se hace la propuesta de erradicar la violencia. 
No voy a extenderme más. Volviendo a la Ley General de Acceso a una Vida Libre de Violencia, vemos que la misma armoniza esos instrumentos en su contenido y, además, en su exposición de motivos fundamenta en el Derecho Internacional el derecho nacional, y eso es un avance importante para muchos países. Si no hubiera ese paraguas de Derecho Internacional a veces las condiciones locales no nos permitirían avanzar jurídicament; nos apoyamos muchísimo en el Derecho Internacional. El derecho a una vida libre de violencia, como está integrado en los derechos humanos, obliga a este reconocimiento. Los derechos deben ser reconocidos para que sean derechos. No hay aquí eso de que yo me siento igual, no, no, tiene que haber igualdad jurídica. No hay aquello de que yo me siento libre, aquí no estamos en qué me creo o me siento, tengo que gozar de libertades que estén enunciadas jurídicamente y en este terreno nos movemos cuando hablamos de derechos. Lo digo porque en muchos ámbitos sociales las personas consideran muy lejanos los derechos, muy lejanas las leyes, como si no tuvieran que ver con ellas mismas. Pero el tema del ejercicio de derechos sí obliga a que estén reconocidos y, además, a que la sociedad y el Estado mismo reconozcan esos derechos. Pero además el Estado debe garantizar el goce de esos derechos, está obligado. Debe garantizar que se ejerzan los derechos, debe proteger esos derechos y libertades.

Aquí están, se los saqué por si nunca habían sabido cuáles son los derechos humanos de las mujeres, se los copié y se los traje. Me vine en un avión de Iberia a traerles los derechos humanos de las mujeres que se aprobaron en la Cumbre de Viena considerando que todos estos derechos son derechos humanos, y también, que sin estos derechos humanos no hay en general derechos humanos. Cada uno puede leerlos, no me puedo detener mucho, pero son derechos que, en la convivencia cotidiana, las mujeres ven violados en muchos países del mundo.

Y dice la ONU, por ejemplo, en un informe sobre derechos y desarrollo, que en ningún país del mundo se respetan a cabalidad los derechos humanos en las mujeres. Pero la ONU sí reconoce, y además lo investiga, que en las sociedades con mayor desarrollo y mayor desarrollo equitativo hay menor violación de derechos humanos. También reconoce que en los países, en las sociedades que tienen mayor democracia, hay mayor respeto a los derechos humanos y a los derechos en general.

Pero, por ejemplo, en todos los países hay mujeres que viven torturas por ser mujeres. Tortura doméstica, o tortura escolar, ahora hasta lo llaman «bullying», o tortura laboral enorme, que no se ve. Tortura en las relaciones diversas en las que están las mujeres, y a veces tortura como castigo a las mujeres por su comportamiento, o supuesto comportamiento. Por hablar de ese. El respeto a la integridad incluye tres dimensiones: la física, la psíquica y la moral. A veces sólo es física, pero de acuerdo con la moral de cada mujer puede haber una violencia específica para atacarla moralmente, para dañarla moralmente. La psíquica es compleja de definir, pero está en el articulado de las leyes ya definidas.

La igualdad es un derecho humano de las mujeres, la igualdad de protección ante la ley, y eso es superimportante. Por ejemplo, puede haber leyes de los talibanes que atenten contra los derechos humanos de las mujeres. Pues esta Cumbre de Viena incluye ese tipo de atentados, que incluso pueden ser parte de leyes, parte de normas reconocidas y aceptadas, pero, en tanto que violentan los derechos humanos, no son reconocidas por este pacto internacional de derechos humanos.

Hay muchas otras. Aunque ustedes no lo crean, hay países en medios modernos y occidentales en los que en algunos lugares recónditos las mujeres no pueden salir de su casa si no piden permiso. Anteayer comentábamos con las mujeres rurales con las que estábamos reunidas en Orduña quiénes salieron de su casa al evento de 300 mujeres sin pedir permiso, y hubo varias que dijeron: «Bueno, pues más o menos»; otras regular, otras tuvieron que dejar todo preparado en su casa para poder asistir a una reunión de 
asociaciones de mujeres; y estamos hablando de Europa, qué les cuento de América Latina y otras regiones aledañas.

Todavía nos cuesta sudor y mucho esfuerzo. Ya no tantas lágrimas, y cada vez menos esperamos otras cosas, pero es la igualdad de acceso a funciones públicas en su país, no sólo, por ejemplo, como la pakistaní que hoy es ministra de Cultura en Noruega pero no podría serlo en Pakistán, que es su país de origen; ella tiene la doble nacionalidad. ¿La vieron también en el periódico? Le dedicaron un reportaje completito. La noticia es que la ministra noruega de Cultura es pakistaní de origen y además es joven, dos condiciones exóticas para ocupar un Ministerio. Pero todavía es raro encontrar mujeres en funciones públicas en su país. No estoy ahora pensando en mujeres políticas que ocupan cargos. No; estoy pensando en otras mujeres que dirigen algo, por ejemplo, que son directoras de orquesta. En México tenemos muy poquitas y la mayor parte de ellas han venido de Estados Unidos. Son mujeres mexicanas migrantes, no las que van a la atención de casas o a cuidar enfermos, no esas, otras que también migran para estudiar. Las músicas que quieren dirigir orquesta se van a Estados Unidos. Allá estudian dirección de orquesta y llegan empoderadísimas, llegan muy empoderadas y muy reconocidas, con un currículum muy amplio porque han dirigido filarmónicas, orquestas de cámara, sinfónicas, etcétera, fuera del país. Ahora ya más o menos empiezan a surgir directoras de orquesta, digamos, «autóctonamente educadas». Pero así podemos ir por todos los ámbitos públicos mirando qué mujeres ocupan altos puestos. También decir que en México ya hay varias rectoras. Tenemos universidades públicas maravillosas, son las mejores universidades en el país, las públicas, de más alta calidad académica y en varias de ellas ya hay rectoras. Incluso en la Universidad Politécnica Nacional tenemos ahora una rectora de lujo. Pero son poquitas, son pioneras memorables.

A todo eso nos referimos, pero sobre todo a las mujeres que están en puestos desde los cuales pueden tomar decisiones. Esto lo mide el programa de Naciones Unidas para el Desarrollo con un índice que ha creado, que se llama de potenciación de género, que mide cuántas diputadas hay, cuántas senadoras, cuántas ministras, cuántas directoras, cuántas presidentas de colegios académicos o de profesionales, cuántas mujeres empresarias están en los consejos de administración de sus empresas. Y se van contando aquellas que ocupan lugares en la función pública. Pero en la mayor parte de los países, a veces, aun teniendo presidentas o jefas de Gobierno, el resto de las mujeres no pueden ocupar posiciones de este tipo.

Esta ley incluye qué es violencia y los tipos de violencia, y de esas diferentes violencias voy a hablarles. Hay otras leyes en el mundo que no incluyen la tipología de la violencia, sólo enuncian la violencia como violencia de género, por ejemplo, pero en esta ley incluimos la violencia psicológica, caracterizada por el tipo de recursos que se usan para violentar, así como por los daños que esa violencia ocasiona directamente.

La violencia física es la que más se reconoce, pero hemos debido transformar la definición porque antes se decía que era aquella en que los golpes o los moratones tardan treinta días en sanar o algo así, o sea, que te tenían que dar una tunda terrorífica para que se considerara violencia física. Lo otro eran empujones, golpecitos normalizados y aceptados. Hemos logrado que hoy todo eso se considere violencia física.

Violencia patrimonial, porque muchas veces al buscar agredir a las mujeres se daña su patrimonio. Se daña a las mujeres a través de objetos, de propiedades o de bienes que son importantes para ellas.

Violencia económica, que abarca muchas gamas de violencia, desde la explotación económica hasta la discriminación salarial. Las mujeres ganan menos salario que los hombres haciendo un trabajo semejante. La gama de violencia económica es amplia. 
La violencia sexual, que como les conté hace un rato estaba tipificada en los códigos penales, pero no estaba incluida en ninguna ley, sólo era un tipo penal, ahora es un tipo de violencia reconocido por la ley como una violencia de género.

Es un típico caso de unas legisladoras que nos preocupamos mucho de no incluir todo; entonces pusimos esto porque seguramente iremos tipificando, seremos más sensibles a otras cosas que no vemos ahora, como nos pasó en el pasado, y entonces por eso pusimos forma análoga, o sea, la violencia implica daño o intención de daño. Esa es la clave de la definición de la violencia, y que dañe todo lo que ya expuse antes.

Estas son las modalidades de la violencia. Les voy a explicar la metodología jurídica utilizada para ver la violencia de género contra las mujeres. Está la definición en la ley, y es importante porque puede ser que cause a la mujer muerte, daño o sufrimiento físico, sexual o psicológico, y abarca tanto el ámbito privado como público.

Voy a comparar, sólo para contrastar. Diré que, por ejemplo, la ley española sólo trata de la violencia de género. Llama violencia de género a la que se produce en el ámbito de relaciones de pareja, y sólo a esa. En el caso nuestro, como nuestra realidad es tan brutal, la referimos también tanto al ámbito privado como al público.

Resumiendo, las modalidades que recoge la norma son: violencia psicológica, física, sexual, patrimonial y económica. En las modalidades de violencia, por el ámbito en el que ocurren, incluimos violencia familiar, que está definida con perspectiva de género. También incluimos la violencia laboral, que es la que sucede en el ámbito laboral, cualquiera que este sea, y la violencia docente.

En la investigación diagnóstica encontramos que en el país, que en México, muchísimas mujeres viven violencia laboral. En las maquilas, ¿conocen qué son las maquilas? ¿No? ¿Maquiladoras? Tampoco. Pues yo les cuento. Son fábricas que producen partes de un producto, que luego se ensamblan. Por ejemplo, en México se producen partes de aviones que no se ensamblan en México, se ensamblan en Estados Unidos y ya salen como un producto que luego le venden al mundo como fabricado en Estados Unidos, cuando fue hecho por partecitas en México, a muy bajo costo. En el mundo, las maquilas pagan bajísimos salarios. El trabajo no está protegido por leyes laborales, no hay organizaciones sindicales, o si hay son corruptas y nefastas. Es un trabajo muy precario el de las maquilas. Y generalmente lo hacen mujeres, o mujeres y niñas y niños, en el mundo entero. El ámbito laboral es un ámbito de muchísima violencia y ahí puede haber violencia psicológica, hay violencia física, hay violencia sexual y hay violencia económica.

Entonces, para explicarles el mecanismo, se combinan todas las modalidades de violencia que ya vieron aquí con todos los tipos de violencia. No es que haya sólo tipos, o sólo modalidades, son tipos y modalidades articulados, y lo que les voy a contar, que es peor, por lo menos en México, no sé en España, pero en México muchas mujeres viven varios tipos y varias modalidades de violencia al mismo tiempo. O sea, no es que de repente una mujer sea violentada, sino que podemos saber que alguna mujer, con trabajo precario en una maquila, es violentada por el gerente, el capataz, por el que está en la banda de producción; por sus compañeros; por el mesero de la cantina a la que puede ir la obrera a tomar una cerveza después de trabajar; o por el cliente en un restaurante; o por un transeúnte que agrede sexualmente y que pasó por ahí. Es decir, que el tema es complicado. Y las violencias son múltiples y muchas veces simultáneas.

También, por ejemplo, violencia sexual incestuosa. Para que les caiga en mente de qué estoy hablando: violencia sexual incestuosa la viven sobre todo niñas y adolescentes. Esas edades son críticas, difíciles, y obviamente cuando lo investigamos y sacamos a la luz tenemos que crear medidas de prevención, de atención, de sanción concretas para esos hechos ahora delictivos contra esas niñas y esas adolescentes. 


\section{¿Más o menos me siguieron?}

La institucional es la que hacen personas que trabajan en las instituciones, sean funcionarios, técnicos, personas que atienden empleados o directivos de instituciones que son responsables de no proteger, no garantizar, etcétera, los derechos. Esa es la violencia institucional.

Para los de Ciudad Juárez, y otras ciudades de mi país, esta violencia institucional es clave porque después de vivir violencia, por ejemplo, feminicidio, los familiares de las mujeres víctimas de esta violencia son maltratados institucionalmente, son violentados y se les impide el acceso a la justicia, o los jueces, o quienes tienen que procurar justicia, retardan la administración.

Es sólo por dilación. Y quiero decir que eso en muchos sitios es un gravísimo problema. Yo todavía guardo la foto de un juez en Madrid que también salió en primera plana de «El País», que está en su oficina rodeado de carpetas y carpetas de expedientes y expedientes, en todos los escritorios, los anaqueles, los armarios... y el juez, ese juez de Madrid, que no recuerdo ahora el nombre, decía: «Estos son los 7.000 expedientes rezagados de denuncias que hicieron mujeres por estar viviendo violencia». Rezagados. Y dice en la entrevista: «Cuando veo las noticias por la noche al llegar a mi casa cruzo los dedos», o algo así. No sé si aquí se dice pero en mi país, con esa expresión se quiere referir a «que no sea una de las mías».

El tiempo de los derechos es exacto. Dejar que pase, que se alargue, le puede costar la vida a las personas. Y por eso hicimos énfasis en la violencia institucional. Ya hay sanciones para faltas administrativas de funcionarios pero queríamos que quedara en el cuerpo, en la ley. No es que el derecho nos haga buenas o buenos, es que los derechos hay que cumplirlos. Si no se cumple, porque tampoco se promueve, entonces hay una falta muy importante institucional.

Y la última, que no está en devengo, que es el producto del horror del feminicidio en México, es la violencia feminicida, que quedó establecida como una modalidad de la violencia, ocurre tanto en el ámbito privado como en el público, y que podemos definir como el conjunto de hechos de violación a los derechos humanos de las mujeres que puede conducir a una muerte violenta de las mismas.

Y para que despierten, porque tienen cara de hipnotizados por el PowerPoint, les diré que hay otras formas de muerte violenta que no son feminicidio, es decir, que la violencia feminicida abarca el feminicidio pero también otras formas de muerte violenta que en mi país son recurrentes.

Están definidos todos los tipos y modalidades de violencia. Quiero añadir, hablando muy bien de la ley española, que esa ley tiene un conjunto de medidas de protección formidables, que además han sido aplicadas ya durante varios años y que han mostrado sus bondades. Decimos, desde la teoría de la violencia contra las mujeres, que la violencia es progresiva y si la violencia persiste quien la hace recurre a hechos más violentos cada vez, y la violencia es crónica y puede ser mortal.

Cuando se aplican medidas de protección ante denuncias de mujeres por haber recibido violencia psicológica, física, sexual... y se aplican en serio, se dice teóricamente y prácticamente que esa mujer ha salvado la vida, porque no sabemos nunca si la progresividad de la violencia en la que estaba enmarcada hubiera ido a mayor, pero es probable que sí. En España se han aplicado un millón de órdenes de protección, un millón de órdenes con las que el Estado ha protegido los derechos y, desde luego, con ello la vida de esas mujeres. Es el único país donde ha pasado eso, tienen que saberlo, porque es importantísimo. En otros países, como México, es complicado pero cada vez procuramos 
que se apliquen más. Tenemos la alerta de la violencia de género, que la inventamos para lograr que sin dilación las instituciones concurran con toda la política que está en la ley para afrontar una situación de emergencia de género.

Yo estoy convencida, y mucha gente que está con nosotros en todo esto, jueces, magistrados, salubristas, personas de diversos ámbitos, que si en Ciudad Juárez se hubiese aplicado la alerta de violencia de género, que no la había, hace quince años, probablemente hubieran salvado la vida la mayor parte de las mujeres que hoy están muertas por violencia de género. Y también decimos que si se aplicaran hoy en los lugares donde hay altos índices de violencia contra las mujeres, muchísimas mujeres podrían evitar ser víctimas de esta violencia.

Hemos pedido ya casi en diez ocasiones diferentes que se declare la alerta de violencia de género en distintas partes del país, por ejemplo, en Chihuahua. En Ciudad Juárez la pedimos y no la han declarado. En lo que se llama Estado de México, que es un Estado gigantesco que tiene I7 millones de habitantes, hay una alta tasa de feminicidio pero tampoco la han aplicado y cada gobernante, da igual el partido en el que milite, considera que si se hiciera la declaratoria se estaría autoacusando de incapacidad institucional o de omisión o negligencia o dilación. Y, por lo tanto, no lo aceptan y hay recursos para no aceptarlo. Lo comento para que se entienda la complejidad del tema.

Respecto a la atención a víctimas, que por ahí me pedían que hablara de prevención, creo que ya les he señalado muchos ejes de prevención de la violencia que involucran todo: la educación, el ámbito laboral, el ámbito de la educación en derechos humanos y muchas otras cosas más. Es importante.

Un año que pudimos por fin saber más o menos con datos oficiales, que antes no se publicaban, pudimos saber que en México fueron en todo el país-somos iıo millones de habitantes, pónganle que somos 55,5 millones de mujeres y niñas- cada año fueron asesinadas I.205 mujeres. Y con ese ritmo, y con esa historia.

En España, que son 46 millones y que, por lo tanto, son 23 y pico de mujeres las que hay hoy, en octubre, ya estamos a mediados de octubre, 37 mujeres asesinadas.

Lo comento para que podamos, por lo menos, conocer esas cifras, gigantescas o pequeñas, pero todas importantes. Es preciso saber la distancia entre países en cuanto a la violencia que implica asesinato de mujeres y niñas. La verdad es que es importante saberlo comparativamente para poder ver qué factores inciden realmente en que haya más violencia contra las mujeres; o qué factores -que, además, sabemos que son múltiples, la violencia está multideterminada- ayudan, favorecen, disminuyen la violencia o propician que no haya alguna modalidad de violencia.

Y eso es importante saberlo para defender esas condiciones de vida que necesitan en positivo la vida de las mujeres y que cambian también la vida de los hombres. No es que se vuelvan buenos, sino que pueden no ser violentos, cosa que ya sería una ganancia maravillosa. En México sería un lujo de detalle que un día se pudiera anunciar «en México hemos logrado que los hombres no sean violentos».

Por la vida y la libertad de las mujeres. Aquí voy a acabar. Muchas gracias. 


\section{Moderadora: $\mathbf{M}^{\mathrm{a}}$ José Clavo}

Si queréis preguntar alguna cosa o comentar, abrimos un turno de palabra.

\section{Olaya Fernández Guerrero, grupo de investigación Igualdad y Género de la UR}

Yo en primer lugar quería agradecerte que hayas tenido la deferencia de estar aquí y de hablarnos de todas estas cuestiones. Me ha parecido interesantísimo todo lo que has planteado y, desde luego, nos invita a sumarnos a la Liga de las Mujeres en México; aunque sabemos de ellas por las noticias y demás, no es lo mismo leer unas noticias que contárnoslo de primera mano.

Y aunque no has querido entrar en detalle en tu estudio antropológico, yo sí que tengo mucha curiosidad por saber por qué en Ciudad Juárez... o sea, en todo México en general, pero qué características peculiares tiene el entorno de Ciudad Juárez para que haya esa sobredimensión de asesinatos o de violencia contra las mujeres. Eso por un lado. Y luego quería preguntarte, como sé que tienes contactos muy fluidos con grupos feministas, con investigadoras españolas y demás, quería preguntarte cómo percibes tú la situación de los estudios feministas en España. ¿Qué salud tenemos las que nos dedicamos a la actividad feminista en España?

\section{Marcela Lagarde}

De lujo.

De lo que planteas sobre Ciudad Juárez. Sólo quiero mostrarte algo para que veas... Es una gráfica.

Este primer mapa es México, más o menos ven cómo es México. Lo que está arriba aquí es Estados Unidos. Primera característica de Ciudad Juárez: Ciudad Juárez está aquí, es frontera con Estados Unidos.

Miren, el tema es este, la clave metodológica y epistemológica es entender que las violencias son multifactoriales, no hay una causa ni un factor, mucha gente ha dicho el rollo de que porque es frontera, sólo porque es frontera.

Sí, pero hay otros lugares fronterizos muy importantes donde no hay el número de casos que hay en Ciudad Juárez, no tienen una tasa tan alta de homicidios contra mujeres y niños.

Chihuahua está en el sexto lugar en tasa de homicidios de mujeres y niñas, es este lugar, todo este lugar. Ciudad Juárez está por aquí, pues por acá, no sé si ven bien estos mapas, pero no importa, se los platico, hay otro lugar que está en la Sierra Tarahumara, allí en el mismo Estado, en otro lugar, hay más alta tasa de homicidios de mujeres que en Ciudad Juárez.

Entonces no es el número lo que es sorprendente solamente, sino otras cosas. Efectivamente es frontera, pero qué frontera. Es una frontera por la que se trafica todo y lo demás. Esa es otra característica muy importante que genera un lugar, un territorio en el que no está vigente el Estado de Derecho. Ahí te la cuento.

O sea, no es algo exótico, es algo endógeno; no se respetan las leyes, la vida en esa frontera, desde hace más de un siglo, es una vida de tráfico, se trafica con todo. Se trafica con personas, allí pasan tráfico de mujeres y niñas con fines de explotación sexual a Estados 
Unidos. Se trafica con personas con fines de explotación laboral, pasan por ahí. Se trafican armas, no sólo para México los grupos de la delincuencia organizada, sino armas que en Estados Unidos se compran en cualquier armería y en México van... bueno, ha habido historias complicadísimas que no les puedo contar sobre el tráfico de armas de Estados Unidos a México y Centroamérica.

En toda la época de las revoluciones y de las guerras en Centroamérica pasaron por aquí muchísimas armas para Centroamérica, de los revolucionarios, de los ejércitos y de todo el mundo. Sólo así puede explicarse, por ejemplo, que en Guatemala hoy, diez años después de la firma de la paz, haya un millón de hombres armados, en un país de i6 millones de habitantes, y que no son del Ejército, son armados paramilitares, grupos de mafias, de sectas... todo eso hay aquí; todo eso.

Se trafican dólares, se lava dinero. Hay muchos sitios de prostitución en esa frontera, de prostitución fronteriza precaria, miserable. Eso en Ciudad Juárez.

Juárez creció de tener 300.000 habitantes a, en unas cuantas décadas, tener I.800.000 habitantes. En una forma desordenada de crecimiento, con una precariedad enorme, de gente emigrante que llegaba a Juárez a buscar pasar al otro lado y no encontraba condiciones de pasar y se quedaba allí, precariamente. Precariamente quiere decir en casas de cartón, se hacen casas con llantas de trailers, llantas gigantes, la gente junta llantas de deshecho y hace su casa allí. Bueno, es muy impresionante Ciudad Juárez.

No hay servicios urbanos, no hay luz, no hay agua y luego hay notificaciones exóticas, se vende la tierra sin tener papeles, la gente la compra, se hacen movimientos sociales, los reprimen, es todo un rollo.

Pero en Chihuahua en general, en Juárez en particular, como en Tijuana, Baja California, todo lo haces «chueco». ¿Aquí se dice «chueco»? Lo haces ilegalmente. Te tienes que sacar una licencia de conducir. Ahí voy con mi compadre, ahí que me ayude, que... y le pasas una «mordida», allá se llama «mordida», unos cuantos pesos te cuesta...

Pero también se trafica con coches, se les llama «coches chocolate», todo el deshecho de coches gringos viene por aquí legal e ilegalmente, se introduce a México y se vende. En todos los pueblos de por acá vemos coches gigantescos, esos así que les encantan a los gringos, pues ahí están en los puebluchos mexicanos donde no hay ni siquiera calles.

¿Pueden imaginar todo eso? Es un tráfico, es una ilegalidad y es una profunda desigualdad la de las mujeres allí.

Luego, también se atribuye a otros factores. También ahí se establecieron al mismo tiempo un cártel del narcotráfico y las maquilas. Pasó al mismo tiempo.

Entonces, hay tendencias sociológicas o analistas que dicen que son las maquilas las que ocasionaron esto, por la precariedad laboral de las mujeres, porque no tienen quien las defienda, porque están sin familias, porque son muchas de ellas madres solas, que incluso dejan a las criaturas amarradas para poderse ir a trabajar, no tienen estancias infantiles, no hay nada.

Y hay una parte de Juárez que es superurbanizada, que tiene todos los hoteles de cinco estrellas... o sea, hay una desigualdad social y económica enorme, eso genera mucha violencia. Y mucha violencia de hombres violentos que violentan a las mujeres y muchos de ellos, además, viven de las mujeres, o sea, además de maltratarlas, golpearlas -hay una altísima incidencia de violencia sexual-, además de eso, hay abuso y dependencia económica de esos hombres machistas sobre las mujeres, que además trabajan para que ellos coman. Y así puedo decir muchas cosas. 
Está el narco, está... lo pueden imaginar narco connubido con funcionarios, con autoridades, con empleados, o sea, que tú ya no haces la diferencia entre quién está en la legalidad y quién no.

Y la gente, los partidos políticos que han dominado el escenario allí están connubidos con grupos, tienen intereses muy importantes y, por ejemplo, han salido en estos años en Juárez, en Chihuahua, a difundir una visión de Juárez como «Juárez, ciudad de paz». Entonces «Juárez, ciudad de paz» es una campaña de los empresarios. Entonces los empresarios, en vez de presionar y obligar a que se cambie la cosa, lo que quieren es que no se hable de los crímenes de Juárez ni se diga nada porque entonces se van a asustar los capitales y se van a ir.

Y luego qué ha pasado, que efectivamente muchos capitales «golondrina» de Juárez se fueron a China y entonces se quedó mucha gente sin trabajo, precaria, sin casa, deambulando. Pueden imaginar qué es eso. Con hombres machines, con armas, con una cultura del reto, de la violencia, de la venganza... eso es fortísimo.

La mayor parte de los crímenes conocidos en Juárez fueron cometidos por conocidos de las mujeres. Una parte de los 550 crímenes en estos años, sólo una parte -que son como 80 casos- son de desconocidos, no se sabe el agresor, o fue alguien en la vía pública o fue alguien que cometió el crimen y huyó y que no era conocido ni parte integrante del núcleo cercano a las mujeres.

Les enseño esto porque el Estado donde hay más alta tasa de feminicidio se llama Nayarit, que es un lugar precioso, que tiene mares, que es una joya -que hay lugares de turismo que no han descubierto todavía, porque van sobre todo a Cancún, muchos, por ejemplo, españoles, llegan a Cancún en Iberia directos a Cancún-.

En Cancún, que está en Campeche, que está en Quintana Roo, también hay una alta tasa de homicidios de niñas y mujeres justo en la ciudad de Cancún, que es la ciudad turística, donde llegan sobre todo turistas gringos, españoles, franceses, alemanes, o sea, no es un turismo nacional.

Allí se van a hacer sus despedidas de solteros y se ponen hasta atrás, no sé cómo se diga aquí, o sea, toman la jarra... Y luego, además, con la fama del tequila que tiene México, ahí los chavos llegan en charters y las chavas a despedirse de solteras, a graduarse de high school o esas cosas, como sea costumbre allá. Y es un lugar donde hay altísima prostitución, se le llama ahora eufemísticamente «turismo sexual» de niñas, son niñas que están allí, explotadas sexualmente, algunas de ellas fueron verdaderamente traficadas.

Y les puedo ir diciendo, esto de acá, donde está más rojo (hace referencia a un mapa que proyecta), se entiende que es más fuerte la tasa de homicidios. Ahora ya le podemos llamar feminicidio porque ya se aprobó, pero en esa época no se llamaba todavía así.

Aquí hay más: estos Estados, a lo mejor conocen alguno, estos tres. Aquí está efectivamente menos alto, pero son Oaxaca, que es un Estado muy bonito y muy etnográfico y hay muchos grupos étnicos, con tradiciones vivas, bueno, qué les voy a decir, creo que tú has estado en Oaxaca...

Guerrero, que ahí queda Acapulco, que antes en los 50 era muy famoso, ahora lo sigue siendo. También aquí, todo lo que les dije de cualquier zona turística de México pasa allí, pero aquí además lo que hay son los grados más altos de pobreza, exclusión y marginación en general y, en particular, de mujeres y niñas. Aquí el feminicidio está asociado a todo eso, igual que acá. Este no es frontera, tampoco es frontera pero tiene esas características que se concentran en ciertos lugares, en ciertas capas sociales y económicas 
de mujeres, y se produce el feminicidio. Si se comprende: cuando se superconcentran las discriminaciones, las desigualdades y la exclusión de las mujeres se produce feminicidio, aquí y en China, por si conocen algún lugar donde pase eso.

Y este Estado (Nayarit) aquí es el cártel de Juárez, es el mismo cártel que tiene asolada Chihuahua y tiene asolado Nayarit, aquí además se cultiva tabaco, producto de exportación, con altos grados de explotación de obreras y obreros que trabajan tanto en la recolección de las hojas y la cosecha como en el guiado de los cigarros que se hacen acá. Y los mismos están controlados por las mafias de las drogas de Chihuahua.

Acá en Veracruz también tienen una tasa importante -no la veo aquí, si alguien tiene mejores ojos que yo, pero no importa...- aquí en todo este lugar, aquí está Guatemala. Entonces de aquí vienen los polleros con los migrantes ilegales y los pasan a México, entran por Guatemala a Chiapas, Tabasco y Veracruz.

En este Estado de Veracruz, que tiene unas palmeras preciosas y unas playas maravillosas caribeñas y es un lujo. Veracruz, allí hay una alta tasa de mujeres muertas por accidentes en las carreteras, yo no diría chocan las mujeres, no, las atropellan. Cómo vas a frenar si lo que va pasando en la carretera es una mujer... no frenas y la matas. Los traileros, los camioneros y los machines en sus coches.

Ese es un tipo específico de homicidio de mujeres que es grave. No todas han sido asesinadas de esa manera, por favor, en ningún lugar hay un estereotipo, pero sí hay ciertas cifras que importan mucho.

Aquí está Veracruz. Está en rojo porque hicimos un estudio de profundidad, los que están en rojo son lugares que estudiamos a fondo y para hacer la investigación nada más escogimos que unos fueran frontera, que unos tuvieran alto desarrollo industrial, que otros fueran predominante o mayoritariamente agrarios, que otros tuvieran alta población indígena para saber si eso modificaba como factor importante las cosas, y así sucesivamente.

Pero tuvimos que escoger también qué partido gobernaba cada entidad federativa, para que ningún partido se sintiera amenazado con la investigación. Entonces aquí hay partidos gobernados por la izquierda, por el PRI, que gobernó setenta años México; en el momento de la investigación aquí gobernaba el PAN, el partido de la derecha, muy ligado a la Iglesia y al Opus Dei.

¿Sirvió más o menos la explicación? Traté de integrar factores. Acá hay una frontera y pasan unas cosas, acá hay otra frontera y pasan otras. Aquí lo que pasa son personas para acá, y para acá fluyen armas y se desarrolla lo que en Guatemala y El Salvador se llaman las maras. Las maras son pandillas muy complejas, armadas, que además tienen influencia territorial importantísima.

Acá no hay maras, acá hay cárteles de las drogas. El otro día también venía en un periódico de por estas tierras que robaron el cadáver de uno de los más buscados de «Los Zetas» al que mataron por equivocación. Lo mataron en una incursión de la Marina, que no tiene nada que hacer en eso pero lo hace, y luego se dieron cuenta de que era él y ya no sabían qué hacer y lo llevaron a una funeraria, y entonces «Los Zetas» robaron el cadáver para dejar el mensaje de que el Estado les vale Wilson, o sea...

Esta tasa de suicidios para hablar de otra muerte violenta de mujeres, o sea, nosotras ampliamos con una perspectiva teórica novedosísima cuáles son las muertes violentas, que no sólo son los homicidios contra mujeres. 
En el estudio que hicimos del suicidio, que lo estudiamos en todo el país, encontramos que este Estado es donde más se suicidan las mujeres. Y es interesante.

Yo les puedo contar cinco horas, porque es interesantísimo.

Este Estado, Yucatán, es el de la Ruta Maya. ¿Alguna persona ha ido a la Ruta Maya? Pues aquí es el Estado donde menos feminicidio hay: el o,6\%. Es, digamos, estadísticamente no significativo.

Es el Estado donde más suicidios de mujeres hay y es donde, analizando la biografía del suicidio de cada mujer, encontramos que son mujeres en extrema pobreza, con enorme marginación y con una vida plagada de violencia sexual, psicológica y económica, y mujeres que, como plantean las teóricas de esta visión de la violencia, son orilladas socialmente al suicidio. O sea, la sociedad no reacciona, no nos compete que haya hambre, no nos compete que haya exclusión, al Estado tampoco, y hoy están deshechas: sin protección, sin seguridad, sin libertades, sin todo lo que ya conté.

Y estos Estados, los que están más rojitos, y vean cómo Chihuahua otra vez aparece no con la más alta tasa de suicidios, pero sí con importante tasa de suicidios. Otros Estados como Guerrero, que también es de una pobreza terrible y una gran exclusión de las mujeres.

Vean esto: es lo que se llama ya en el mundo «mortalidad materna», que nosotros incluimos. Por cierto, me encontré hablando de estudios feministas en España a una colega en la Universidad, en Sevilla, que también considera la mortalidad materna como orillada por la falta de atención al desarrollo de las mujeres y a la calidad y salud de las mujeres. La mortalidad materna se produce por aborto, por secuelas del parto o durante el parto, en el puerperio o después, pero están ligadas todas a la salud reproductiva de las mujeres.

Esta también la incorporamos porque entonces dijimos que la salud es un eje fundamental en la vida. Vamos a ver cómo está, en los lugares donde hay feminicidio, la salud de las mujeres: la salud sexual y reproductiva. En este caso es el cáncer cérvico uterino, también aquí es Chiapas. Ese es un Estado que se puso famoso porque aquí se alzaron los zapatistas. ¿Supieron de los zapatistas o les pasaron?

\section{Participante sin identificar}

Sí.

\section{Marcela Lagarde}

Y luego hubo zapatistas por acá, ¿no? Yo me encontré comités zapatistas hasta en Venecia. Les juro que sí, la comuna de Venecia es zapatista y ha financiado, por ejemplo, la luz eléctrica en varios poblados de Chiapas, donde hay una terrible miseria y exclusión social. Aquí el cáncer cérvico uterino es terrible y, si se fijan, está ligado a condiciones socioeconómicas, de desarrollo, de salud, de no vigencia de derechos humanos, como dice la Ley que sigue.

Esta zona es de cáncer de mama. El cáncer de mama está acá, acá están los fertilizantes, los químicos agroindustriales, los basureros que vienen y tiran, las empresas químicas en toda esta frontera. Pero abarca todos los lugares.

Y vamos encontrando correlaciones, eso es lo que les quiero mostrar. No es sólo un indicador, son diversos indicadores y lo que pone en riesgo a las mujeres es su 
debilitamiento de género. ¿Quieren que se lo cuente otra vez? Su debilitamiento frente al poder violento de los hombres, el Estado de violencia y de crispación donde viven y todas las exclusiones que les he contado.

Esta es la gráfica, que ya enseñé. Chihuahua-Ciudad Juárez está aquí, todos estos otros Estados tienen más alta tasa de homicidios y no son famosos, con eso concluyo. Lo raro de Ciudad Juárez fue la reacción civil que hizo visibles los crímenes. En estos Estados del país no ha habido reacción para enfrentar los crímenes, ni siquiera sabe la gente que en su entidad hay esos crímenes, como antes no sabía de Juárez.

Entonces lo que confluye en Juárez, lo que potencia el horror es que lo conocemos, porque las organizaciones salieron de ahí a difundirlo por el mundo y han tenido un éxito mediático durante muchos años, muy importante, que no sirvió para detener los crímenes. Como esta Ley, que todavía en su aplicación no sirve para detener esos crímenes. O sea, mucha gente dice que con todas las leyes siguen matando mujeres, porque lo que hay que resolver es todo eso que les conté, para que no se encubra la violencia contra las mujeres y muchas cosas.

Luego, de estudios feministas en España; en España, en muchos lugares diversos, porque no es parejo, en todas partes, son un lujo y son un referente para América Latina. En este lado del mar están muchas maestras nuestras.

Ustedes tienen grandes filósofas, se conocen en el mundo por sus filósofas. ¿Ya lo sabían? Pues reconózcanlas un día de estos.

Bueno, reconocidísima y queridísima Celia Amorós, es nuestra maestra, es fundadora, es creadora de una corriente filosófica en el feminismo, de investigación histórica del feminismo, de epistemología feminista... bueno, un lujo en la filosofía.

Otra, les cuento otra, Amelia Valcárcel, de Asturias, que es un lujo, esa es otra de nuestras maestras, hace filosofía y ella es experta en ética y en política feminista.

Otra filósofa: Rosa Cobo, que estudia la Ilustración y es una maravilla.

Historiadoras... tienen grandes historiadoras, antropólogas maravillosas. Mañana vamos a oír a Virginia Maquieira, antropóloga madrileña de origen argentino, Vicerrectora de la Universidad Menéndez Pelayo.

Y así puedo ir diciendo por universidades que conozco, pues se distinguen por líneas de investigación, por materias... y hay juristas muy importantes en España también.

\section{Raúl Susín, profesor de Filosofía del Derecho de la UR}

Ha habido alguna referencia a la capacidad del Derecho como instrumento de cambio social y yo soy moderadamente escéptico con la capacidad del Derecho para hacer buena a la gente; moderadamente, es decir, tengo dudas pero creo que si no hubiera Derecho viviríamos constantemente en una especie de círculo vicioso de las desigualdades. Gracias a los derechos podríamos avanzar hacia un círculo virtuoso, pero creo en esto de forma moderadamente escéptica, teniendo presente que el Derecho no lo es todo y que desde luego Derecho y poder no es lo mismo.

Al margen de esto, querría plantear un par de cuestiones. Una tiene que ver con que me llama la atención el tema de Chiapas y que las dos primeras diapositivas que ponía, la de los suicidios y la de los homicidios, tuvieran índices tan bajos en Chiapas, y no sé si es una especie de interpretación romántica o si realmente tiene que ver con la existencia del 
Frente Zapatista o Ejército Zapatista. Creo recordar que el Ejército Zapatista sí que intentaba visibilizar también el papel de la mujer con, por ejemplo, el protagonismo de la comandante Ramona que creo que falleció hace unos años, o también creo que establecieron unas normas donde se prohibía a los hombres consumir alcohol, lo que se puede interpretar como un intento de evitar situaciones de violencia intrafamiliar; es decir, que parece que había una preocupación desde el Ejercicito Zapatista para que se corrigieran situaciones de violencia. Ya digo que no sé si hay relación o si es una visión un tanto romántica.

Y la otra cuestión es que en este mismo Seminario en el que nos encontramos hace unos meses, en abril, vino invitada Teresa Fernández de la Vega, que fue vicepresidenta del Gobierno de España y que es una mujer que ha tenido mucho que ver con iniciativas legislativas relacionadas con el tema de género. Aunque reconozco mi desconocimiento en la materia, a mí la impresión que me dio del discurso de Teresa Fernández de la Vega es que nos remitía a una especie de feminismo de la diferencia. Me daba la impresión de que se inclinaba porque fueran las mujeres quienes decidieran cuestiones de este tipo. Por ejemplo, que fueran las mujeres las legisladoras en una ley sobre violencia de género; o que fueran mujeres las encargadas de aplicarlas.

En relación a esto -y no sé si mezclo cosas-, yo no sé exactamente cuál sería su posición, cuál sería para Usted el modelo más correcto: un modelo de feminismo de la igualdad o de la diferencia. Si hombres y mujeres serían los que tienen que hacer esas leyes; o pongamos el caso concreto de este grupo de estudios de género e igualdad, ¿`sois todo mujeres, no?

\section{Participante sin identificar}

Hasta ahora sí.

\section{Raúl Susín} especie de...

Pues la cuestión estaría en si tendría que haber hombres también allí o esto es una

\section{Participante sin identificar}

No está prohibido.

\section{Raúl Susín}

No, pero yo me lo planteo para poner un ejemplo, para a partir de allí qué sería lo más correcto, un feminismo de la igualdad, de la diferencia...

\section{Marcela Lagarde}

Te contesto.

A ver, lo de los zapatistas es bastante romántico, bastante. O sea, que también hay un culto ahí al amor, ¿por qué no? Es un ejército levantado en armas de madera, ¿no?

Pero efectivamente las mujeres zapatistas en sus años de formación y de organización comunitaria en una región de Chiapas hicieron la Ley de las Mujeres, con seis 
artículos. Yo fui asesora de las zapatistas en los diálogos de paz y en mi bibliografía cuento que ellas hicieron un gran esfuerzo por incorporar una visión, ni siquiera de igualdad, más bien de equidad entre mujeres y hombres. Pero en un ejército esto es complicadísimo. Para empezar hay un «supremacismo», jerarquías y muchas cosas. Efectivamente hubo comandantas, hubo mujeres, que estaban en desigualdad, en minoría, y sí, no dejaron de ser mujeres indígenas marcadas por todas las discriminaciones; pero además hubo una gran idealización, sobre todo de afuera, como si ellas ya hubieran resuelto o porque Marcos hubiera decidido alguna cosa ya estuviera todo resuelto.

No, lo que queda del Ejército Zapatista está entre municipios indígenas, muy pobres, muy marginados, muy excluidos; y después de años del levantamiento ocupan un territorio, que se llama «los caracoles», donde se proponen hacer una especie de aldeas autónomas, autosuficientes y autosustentables. Esa es la utopía.

Pero bueno, funcionan como un ejército, tienen castigos, tienen normas. Por ejemplo, entre otras cosas allí hubo rupturas importantes con el movimiento de mujeres y el movimiento feminista cuando nos llegaban denuncias de mujeres castigadas en el ejército zapatista a la usanza indígena de su comunidad porque su marido se puso «bolo», como dicen en Chiapas. O sea, si el marido se emborracha, como está prohibido, la responsable es la mujer y hay que castigarla. Y bueno, allí empezó a haber un enorme disenso entre el Ejercito Zapatista y grupos de apoyo de mujeres y feministas que estábamos allí por la paz.

Pero en mi caso fue una experiencia muy inolvidable, interesante, compleja, contradictoria también, de ser asesora para ellas, tres comandantas que hicieron el diálogo por la paz, en una mesa que lograron que específicamente tratara la problemática de género y clase y etnia de las mujeres zapatistas. Y eso fue un avance enorme, ahora todo eso se ha diluido y se acabó. Llegaron a... bueno, qué les voy a contar, por primera vez en la historia una mujer no diputada tomó la palabra en el Congreso desde la tribuna y fue la comandanta, no fue Ramona, creo que la comandanta Esther, una maestra indígena que hizo un discurso formidable, que está hecho a muchas manos, obviamente, pero que fue la voz de las mujeres zapatistas en la tribuna más alta del país.

Porque esos alzados y alzadas, hicieron en México algo que es absolutamente surrealista, después de varios años emprendieron una marcha por el país, siendo insurrectos, una cosa increíble; pero además iban cuidados por el ejército y por las policías y llegaron a muchos lugares del país y de regreso a Chiapas fueron al Zócalo de la Ciudad de México, que es una plaza, la plaza mayor, donde está la Catedral, el Palacio Nacional, el Palacio del Ayuntamiento de la ciudad y creo que el Monte de Piedad está al otro lado, ¡imagínense! Y ahí llegaron y llegaron rodeados de miles y miles y miles, y apoyados por millones, y se regresaron a Chiapas y dijeron: «No, no le entramos a la política»; y se fueron. Entonces tampoco resolvieron esa parte que era muy difícil que la resolvieran ellos.

Luego lo de que si mujeres y hombres pueden trabajar estos temas por igual. Ojalá que así como hay hombres que fueron público en esta conferencia, que investigan tantos temas, que estudian tantas cosas, sería muy importante que estudiaran desde esto que llamamos perspectiva de género, que más que un campo es una visión que abarca un gran campo del conocimiento, distintas ciencias, distintas problemáticas. No todas estudiamos la violencia, estudiamos el arte o estudiamos otras cosas que son materia de interés para mujeres y hombres. Ojalá haya hombres que se interesen en esta gran innovación académica, científica, filosófica, política que significa el feminismo y su aplicación, su ámbito académico, universitario... sería maravilloso.

Y luego, la citada María Teresa Fernández de la Vega es admirable, es un referente importantísimo, impulsora de las leyes, no sólo de la de violencia, sino también de la de igualdad y de la de dependencia en España. Fue Vicepresidenta y es una mujer entrañable, 
yo la respeto muchísimo, me encanta, le aprendo cada vez que abre la boca o nada más con su presencia, o sea, ella va con todo eso que dije hace un rato: la dignidad, la integridad, las libertades... va de eso, es un referente emblemático, porque además hay la posibilidad en este país de que haya mujeres que puedan reunir todos esos derechos y que luego tengan conciencia de género y quieran extenderla a las demás. Esto me parece formidable; y que quieran transformar a los señores también en la política me parece importantísimo.

En relación con esto, también decir que el gobierno paritario igualmente fue un aporte; duró lo que duró, pero ya se pudo realizar y eso es una muestra para que aprendamos todo el mundo que sí se puede, y ojalá vuelva.

Y bueno, su opinión de que ella escogería una mujer para trabajar en estas cuestiones, pues yo para muchas cosas también, porque estamos más capacitadas, somos las especialistas en este campo de estudios, tenemos la experiencia, tenemos muchos años de investigación, de docencia, hemos hecho un camino muy importante. Entonces en ese caso sí, para hacer este tipo de cosas sí.

Luego, ya en general y a lo bestia, impulsar que ingresen mujeres a algún sitio, también. Por ejemplo, en México hemos reformado la ley electoral. En la Cámara de Diputados, con todo y con una cuota del 30\% no llegábamos y no llegábamos, no podíamos pasar el $22 \%$, hasta que un día decidimos cambiar la ley electoral, sólo para lograr que lleguen más mujeres. Quién sabe qué van a pensar esas mujeres, quién sabe por qué van a votar esas mujeres, pero llegaron muchísimas mujeres, nunca habíamos tenido tantas, $47 \%$ en la Cámara de Diputados y $38 \%$ en el Senado. Estamos felices y ha sido una iniciativa plural de mujeres de todos los partidos políticos que nos aliamos simplemente para eliminar la exclusión de género del Congreso.

Entonces allí estamos empujando a todas para que entren, de cualquier color, de cualquier ideología; incluso, algunas votarán en contra de avances de las mujeres, pero habrá muchas otras que por estar allí y con el «ambientazo» feminista que ya nos traemos en el Congreso, yo estoy segura que vamos a hacer muchas cosas, y muchas de ellas han suscrito la agenda de género. Se trabajará como cada una pueda en su partido, pero juntas, esa es la clave. Ahora tratamos de trabajar mucho con alianzas políticas de género, o sea, que lo que importe sea qué agenda, qué parte de la agenda de género podemos apoyar todas. La que no, pues no. Y así estamos, experimentando la política.

Pero el proceso no es ejemplar, está cada quién como pueda.

\section{Valeria, trabajadora social} tenerla aquí.

Me llamo Valeria, yo también quería agradecerle porque ha sido un disfrute

Yo, como trabajadora social, quería preguntarle, remitiéndonos a la Ley General de Acceso... con esa perspectiva tan amplia en modalidades -más amplia que la nuestra española, pues, evidentemente, como marco normativo estupendo para remitirnos a él y desgranar un sinfín de recursos-, con esa perspectiva tan ambiciosa, cómo habéis conseguido vertebrar esos recursos, porque claro, tienen que ser recursos personales, institucionales, técnicos, normativos... muy complejos. Además, atendiendo a las especificidades contextuales que hemos ido viendo, y también atendiendo a ese freno que muchas veces da la falta de compromiso político, en manos mayoritariamente de los hombres.

Porque hemos estado hablando de un porcentaje de mujeres a nivel estatal, a nivel central, pero quisiéramos saber también si a nivel local se refleja esa proporción de mujeres 
al mando o gestionando la política, ya que muchas veces este es el nivel que realmente define el recurso directo, el que va a ayudar a la mujer. Si habéis conseguido trabajar en red, si habéis conseguido estructurar las tres administraciones, todos los ámbitos que son tan importantes porque, desde la visión feminista, la red es fundamental por el especial caso que es, ¿no?

\section{Marcela Lagarde}

A ver, la red sí, tenemos muchas redes, si no no estaríamos aquí, tenemos redes incluso transatlánticas, así es.

Pero el tema es que en unos cuantos años todo eso que dijiste, «habéis logrado»... no; nada, nada. Hemos logrado 32 leyes, cosa fuerte, porque somos muy pocas y estamos en red en el país, no abarcamos en esta causa a todo el país y todas tenemos muchas camisetas, trabajamos por los derechos de las mujeres, esto es una parte, y tenemos un país gobernado por la derecha... Te puedes imaginar.

A la derecha no le interesan los derechos humanos de las mujeres. Hace como que hace, simula y bueno, ahí entra nuestra participación; nosotras vigilamos el cumplimiento de la Ley.

Por ejemplo, en mi red, esa red de investigadoras por la vida y la libertad de las mujeres, tenemos como causa profunda empoderar esta Ley, ese marco jurídico de una Ley general y 32 leyes locales. En un país complicado, gobernado por la derecha, que de verdad simula mucho. Y luego, localmente, otros partidos que tampoco ayudan.

Yo pienso que para que esto se aplicara así tendríamos que tener otro bloque distinto gobernando, muy diferente, para poder articular la política en los tres niveles, para poder hacer de esto una verdadera política de Estado, que eso es lo que propone esta Ley.

Entonces va cumpliendo parcialmente con muchas deficiencias, con poco profesionalismo y con muchos obstáculos y con falta de recursos; aunque esta Ley, la de igualdad, la dotamos de un presupuesto muy amplio. Las mismas diputadas que la hicimos logramos la aprobación de los presupuestos para que funcione, pero que funcione esta Ley... Por ejemplo, en todos los capítulos de la Ley se plantea la formación especializada de grupos que tienen que aplicar la Ley. Pues hacer eso nos ha costado muchísimo trabajo.

Estamos apenas capacitando jueces, juezas, magistrados, magistradas, a veces ministerios públicos; pero las universidades todavía no enseñan estas leyes, como no enseñan la de España ni la de Brasil, que son formidables, ni estos instrumentos de los que hablé. Y vamos poco a poco, se enseñan en seminarios, en diplomaturas de estudios feministas, pero eso son ínsulas en un mar de otro tipo de Derecho muy androcéntrico.

En fin, que si aquí, que les conté la diferencia con allá, pasan todas las cosas que pasan, pueden imaginarse allá que tenemos menos distribución de la riqueza, hay una enorme inequidad en México, y también tenemos menos desarrollo de la democracia, aunque les parezca lo que sea. Y sí tenemos leyes potentes, si no, no hubiéramos logrado estas cosas.

\section{Moderadora}

Aunque quedan muchas otras cosas y sigue habiendo interés por tratarlas, parece que el tiempo ya no da para más y tenemos que despedir a Marcela. Así que muchas gracias Marcela Lagarde. 